\title{
Converting to Open Access. The Austrian Journal of Political Science (OZP) as a case study
}

\section{Thomas König}

Institute for Advanced Studies, Vienna (IHS)

koenig@ihs.ac.at

\begin{abstract}
Open Access is a simple idea that has resulted in a confusing landscape of business models, competing policy prescriptions, and vested interests. Academic debates about the pros and cons of Open Access publishing often lack insights into the operational needs for setting up an Open Access publication. This is true particularly for the social sciences, where experiences with Open Access from the production side still seem sparse. Covering the period between 2010 and 2015 , this article recapitulates one of the few cases where an existing academic journal in political science has been converted to an Open Access publication. The Austrian Journal of Political Science (OZP) is an Open Access journal since 20I5; and it was the academic community that conducted the conversion process. Remaking the OZP may thus entail some broader lessons for the social sciences communities about what is important in Open Access publishing.
\end{abstract}

\section{Keywords}

Academic Publishing, Austria, Open Access, Peer Review, Social Sciences

\section{Konvertiert zu Open Access. Die Österreichische Zeitschrift für Politikwissenschaft (OZP) als Fallstudie}

\author{
Zusammenfassung \\ Publikationsinfrastruktur ankommt, die auf Open Access setzt.

\section{Schlüsselwörter} \\ Akademisches Publikationswesen, Open Access, Österreich, Peer Review, Sozialwissenschaften
}

Open Access ist eine scheinbar simple Idee für das akademische Publikationswesen, die zu einer verwirrenden Landschaft von Geschäftsmodellen, Policies und Eigeninteressen geführt hat. In den zahllosen Debatten zu Vor- und Nachteilen von Open Access fehlen oftmals die operativen Einblicke, was eigentlich gebraucht wird, wenn eine Open Access Publikation eingeführt wird. In den Sozialwissenschaften scheint dies besonders der Fall zu sein, nicht zuletzt, weil hier wenige Erfahrungen mit Open Access existieren. Der vorliegende Text rekapituliert einen der frühesten Versuche, ein bestehendes akademisches Journal in Politikwissenschaft in eine Open Access-Publikation umzuwandeln. Die Diskussion dazu begann um 20IO; seit 2015 ist die OZP ein Open Access-Journal. Da diese Konversion von der politikwissenschaftlichen Community selbst geleitet und durchgeführt wurde, enthält diese Geschichte einige breitere Ansatzpunkte darüber, worauf es bei einer sozialwissenschaftlichen

The author has declared that no competing interests exist. 


\section{Introduction: why Open Access?}

Two major trends have dictated much of the history of academic publishing in the past three decades. Since the early I990s, there was a strong orientation towards "publish or perish" and, more precisely, the need to publish in journals listed in one of the major bibliometric databases (Clarivate's Citation Index and Elsevier's Scopus). A decade later, the idea of making scientific literature openly accessible was gaining traction. Interestingly, though maybe not surprisingly, disciplines from the "hard" sciences lead both of these trends, with the social sciences usually lagging behind for about a decade. While this is not necessarily a bad thing, the social sciences do not seem to take the unique opportunity available to them as "late adopters" - to learn from the mistakes made thus far and to try to avoid them.

In the case of "publish and perish", at least, the unintended consequences were already on display in the early 200os: incentivising the publication of small pieces of research results, driving up the overall workload for peer reviewers, undermining the inherent quality assurance measures, which even lead to an increase of fraudulent behaviour and manipulation of data (Fischer 2008; Fanelli 2010; Biagioli/Lippman 2020) because it forces scientists to produce "publishable" results at all costs. Papers are less likely to be published and to be cited if they report "negative" results (results that fail to support the tested hypothesis). Yet it was at that point in time that the social sciences (and the humanities) started implementing this normative framework with force, which led to similar results (Moore et al. 20I7). And today, almost two decades after the simple idea of "free and unrestricted online availability" of peer reviewed journal articles was publicly stated (Budapest Open Access Initative 2002) and with an ambitious though ambiguous "Plan S" in place, the question of Open Access still remains unsettled: are we following the trails of the natural sciences again? Or can we learn from what they have experienced?

For a long period of time at least, the social sciences' restrained reaction to (or, less diplomatically, ignorance of) the Open Access movement implies that its main organisations and associations have had only little practical expertise with its publishing models - and little interest in developing one. This is unfortunate, in my opinion, and also all the more troubling as the simple idea of Open Access actually resulted in a confusing landscape of different business models, competing policy prescriptions and strategies and vested interests (Hagner 2018), including a curious phenomenon like "predatory journals". Discussions about how to develop a common strategy of utilizing the opportunities of free publishing for the better of social sciences have been triggered belatedly; yet still, if those discussions take place, representatives from publishing houses and librarians, equally eager to push their institutions' interests, try to capture them (Bull 2016).

The following text recollects the author's personal experiences with converting an existing political science journal, the Austrian Journal of Political Science (Österreichische Zeitschrift für Politikwissenschaft, OZP), into a truly online-only journal that is freely available. Its ambition is to add some practical insights and to document the main arguments for this momentous decision. By recapitulating the conversion process between 2010 and 2015, the text aims to answer two questions: why did the journal management decide to fully shift the journal to Open Access? And what are the lessons to be learnt from the ensuing experience? After a brief reiteration of the process, some of the changes and their impact on the journal's perception from within as well as from outside Austria are discussed; finally, it returns discussing some of the broader implications of Open Access for the future of academic publishing in the social sciences.

I should state upfront that, while I have been a driving force behind this change for more than six years (between 2010 and 2016), I am no longer with the journal. In retrospect, the project that I was responsible for entailed two consecutive steps. The first was to initiate, and guide, the discussion within the Austrian political science community about which route the journal should take at a critical juncture of its history; here, the conclusion was that the journal - until then, published in print-only - should go Open Access. The next step, beginning in 2012, was more practical, namely to actually convert the journal to Open Access. Among other things, this meant to reorganise the journal's editorial structure, set up a new business plan, and design a technical and procedural framework for article submission, reviewing, and publishing aligned with Open Access standards. Operatively, this transition was successfully concluded by the end of 2015 - a good point in time also to hand over managerial duties of the journal to someone new. Nonetheless, I am keen on the future success of the journal and its management.

\section{A brief history of the OZP's transition towards Open Access}

Up until today, national journals constitute the vast bulk of all social science outlets in Europe (Heilbron et al. 20I7). Founded and owned by the Österreichische Gesellschaft für Politikwissenschaft (ÖGPW)/Austrian Political Science Association (AuPSA), the OZP has existed since 1972. In the late aughts of the new millennium, the venerable journal faced a predicament. Partly, this was because of missed developments in academic publishing. Unlike most of its peers, the OZP has not been taken 
under the wings of one of the major journal-publishing houses present at that time. Instead, it was published by a relatively small Austrian publisher focusing on academic monographies, mostly in German. The advantage of this collaboration was that the journal was supported excellently in the editing process; the downside, however, was a lack in visibility. The OZP was published in four issues annually, most of them being "special issues" with only few freely submitted articles in addition. There was a "moving wall" of three years after which the articles were published online on a (static) website, with no further metadata harvesting and no linking to indices.

Unlike other journals, the OZP was not bringing in extra revenue (Bull 2016). With political science in Austria being an underrepresented discipline (König 2016), the ÖGPW, with about 600 members, was lacking the resources and manpower to ensure that its journal could be maintained by a dedicated staff. In 2014, the journal had an annual budget of approximately 25,000 Euro (not calculating in kind contributions from those who contributed to the ongoing production of issues and who were basically rewarded in academic reputation). Besides the subscription fees (approximately 800 subscriptions to the journal existed, most of them libraries and members of the Austrian association), this included an annual subsidy by the Austrian press council in the amount of approximately one third of the annual budget. All in all, the journal carried itself, but it had no paid managerial staff (and compensated the assistant editors only with a symbolic sum). It had become a tradition that it was taken care of by a handful of staff scientists and post-docs.

It was clear to those involved with the journal that, at this point in time, there were four developments in the academic world that put the journal as such increasingly at risk of becoming irrelevant. First and most ominous was the fundamental shift in the reading behaviour of (social) scientists. Due to digitisation, scholars were getting into the habit of searching (and finding) their literature online, with the inherent expectation increasing that also the full-text of any given article should be electronically available for download. For potential authors, publishing in a print-only journal, then, meant to be hidden away from the academic public.

Second, and related to the first point, was the fact that bibliometric analysis had started to play a significant role in determining the research productivity of individuals, departments, and universities, based on data provided by bibliographic databases (by the time, mostly SSCI and Scopus). Obviously, journals listed in those databases are deemed more relevant by research managers (since publishing in them increases the productivity), and, as an unintentional (but very relevant) consequence, this soon was reflected in the reputation of journals among researchers and scholars too: a "SSCI journal" was per se deemed to be of higher quality (note that I do not qualify this statement and only report it for historical documentation). The OZP was long listed in the SSCI, and the editorial team collectively wanted this privileged status to continue, which is why print-only was increasingly perceived as detrimental. After all, the bibliometric databases were digitalising too.

Third, the journal's business model was relying on an annual state subsidy and the income from a (slowly reducing) number of subscriptions and on the de-facto unpaid work of the editorial team of (mostly) post-doc and assistant professors who managed reviews and editing of journal issues. There were several question marks involved with the long-term viability of this model: as journals were no longer read as such, subscriptions would probably dwindle further. If - which is never an unlikely outcome - the state subsidy would cease, the entire journal would be in peril. This too, then became an area that needed to be tackled proactively.

Finally, there is heightened attention to how fair, and well-argued, a decision-making procedure is - and rightly so. Up until 20I0, however, the journal did not have written guidelines for the review process, and no policies to coordinate in case of contradictory results. Also, the procedural steps of reviewing, and deciding on, article submissions were not systematically documented. It goes without saying that everyone involved put up their best effort, yet the lack of a common policy sometimes resulted in decisions that one would find difficult to reconcile, and because of this, individual submissions occasionally turned into long-winding and cumbersome procedures. It was clear to everyone involved that to maintain the quality of the articles published in the journal, its review procedures needed to be defined, written down, and published.

Two alternatives were discussed. One was to sign a contract with one of the major publishing houses, the other one was to embark on Open Access. Initially, neither of the two alternatives was discussed very positively. There had been plausible reports by colleagues with similar responsibilities at other academic journals about the various downsides when dealing with any of the major publishers: the journal would become one among thousands of others, with little interest in particular needs. It would have been taken up and distributed in bundles. But of course, there would have been advantages. The discipline internationally was, by this time, simply convinced by the idea that a major publisher was like a quality stamp. Second, some circumstantial services - most importantly, recording of the journal's newest issue in various online databases - would have been ensured by the publisher as well.

Even riskier to many was the road towards Open Access. While it was acknowledged that online communication was the future of academic publishing, and 
while the Open Access movement was already well established in other niches of the academic landscape, the political science community was still sceptical. There were many predatory journals with "political science" in the title out there; and there was a common understanding that, allegedly, Open Access would imply a slack in quality control. Nonetheless, internal debate continued and, eventually, became more positively attuned towards Open Access.

In 2012, the Austrian science funding agency, FWF (Fonds zur Förderung wissenschaftlicher Forschung), opened a funding call to offer seed money to journals in the social sciences and humanities for the purpose of changing to an Open Access journal. The FWF is among the funding agencies in Europe that have been pushing for Open Access aggressively for quite a while already (Bauer et al. 2015). Thanks to the intense discussions that had begun two years earlier, the journal's editorial team was in a good position to come up with a competitive proposal which was submitted in due time. Based on three positive reviews from international peers, the proposal was accepted, and in late 2013, the contract was signed between the ÖGPW, the FWF and Innsbruck University (the latter as the designated long-term institutional partner). In order to orderly determine contractual obligations, it took until 2015 for the journal to ultimately be published as an Open Access journal (König et al. 20I4).

\section{What has Open Access done to the journal?}

For a while, hardly anything was a nearly as heated and emotional topic of debate as Open Access, and the topic has proven to be on shifting grounds - opposition has mostly changed from outward scepticism and ignorance some years ago to grudging acceptance nowadays, while advocates themselves seem to have developed from sometimes feverish activism to more pragmatic standpoints. Even so, it is sometimes difficult to remain focused and discern ideological statements from more pragmatic aspects of changing a journal's publishing mode to free online availability. In that respect, it may be interesting to ask how (and if) the shift to Open Access has changed the journal. I discuss four aspects: the journal's perception in the community, its mechanics, its business model, and its self-understanding. First, and most importantly, what has it done to the selfunderstanding, the mission of the journal? I should add immediately that this discussion is restricted to the time I was personally involved with the journal, up until late 2016, and while I believe that those observations still mostly hold, some of them may be historical; in that case, I would hope (and am looking forward to) additions and comments from those now in charge.
As a national medium of a smallish disciplinary association, the OZP was never expected to play in the first league of academic journals in its domain. Most of all, it was supposed to serve as a forum for the members of the national association, and as a platform to present results of their research to the wider academic community, particularly on topics of national, regional, and European relevance. This self-restriction did not mean, however, that the journal had a somewhat lower requirement when it came to quality. From the beginning, the journal regarded itself as part of the international political science journals, committed to the standards of good scientific practice.

It is (or has been, for that matter) a misunderstanding of many colleagues in the discipline that Open Access per se would mean a downturn of quality. For the OZP, at least, it is the contrary. Open Access is seen as a promising niche and as an opportunity to focus more on the imminent needs of an academic journal and to let issues such as printing, subscriptions, and other topics vanish. The opportunity was that submissions, if reviewed positively, would be published faster and would have more visibility because they were online from the very start. (It should be recognised, however, that up until now, the journal is published in the traditional mode of four issues per annum.)

Second, how has the modus operandi changed? Given the fact that the journal did not intend to alleviate from its stance on editorial procedure and quality control, long-established and well-known policies that mark an academic journal were taken explicitly as important preliminaries for the OZP as it was becoming an Open Access journal. It was therefore without question that the quality assurance process, namely the double-blind peer review of each submission, would be continued. In a similar manner, the editorial process would ensue in a timely and efficient manner. Finally, it was also deemed a priority that the appearance of the journal's articles would be printed in a sophisticated mode.

Some improvements were made. Most importantly, now there was a paid position for a managerial editor who was responsible for the journal overall. One of the main tasks of this person was to oversee the entire workflow of the journal and to fixate more clearly the role of those involved, therefore providing more routine to all aspects of editing article submissions and preparing journal issues for publication. Another important improvement was the implementation of a content management system specifically for Open Access journals (called OJS), which brought more transparency within the journal's editorial team, as well as better documentation. Other features that have long been established included a reviewer database, for example. Furthermore, this was the opportunity to modernise the journal during this process, with several features (metadata 
harvesting, access to important new databases such as DOAJ, new contract to DOI, etc.) added.

With regard to the underlying business model, due to the initial funding by the FWF and the commitment of the Innsbruck University to carry costs for the parttime employment of the managing editor as well as in kind the hosting of the online platform and copy-editing of articles, the journal could begin establishing a longtime planning perspective of at least five years (unlike the one-year-basis before). This was true for the period of 2012-2016; I understand that, in the meantime, the Innsbruck University has contractually extended its commitment to support the journal, which is a clear sign that the initial project resulted in a reliable partnership between the university, the ÖGPW (as the journal's owner), and the editorial team. Equally important, a better usage of scarce resources on quality assurance and editorial work could be achieved. By 2015, the annual budget of the journal has been downsized approximately to half of what it was before Open Access, which means that the financial obligations have lessened for the owner. Instead of approximately 70 per cent of the annual budget being spent for costs such as setting in type, printing and distribution, now almost 80 per cent of the overall budget is covering costs related to editorial work and quality assurance.

Finally, how has the perception of the journal changed? This is probably the most difficult question to answer, simply because perception is changing rapidly nowadays and there is no robust way of understanding how the political science community relates to a journal like the OZP, if the journal is known to them at all. Given that the problem of the journal was its lacking visibility, I took it as a positive sign when the number of free submissions of articles have been increasing from 2015 onwards, even though this does not tell us anything about the quality of the draft submissions. Indeed, for the time when I was still managing editor (up until late 2016), the number of desk rejections was about 50 per cent for those articles, which indicates that more visibility also implies that it attracts more half-baked material.

One important decision with respect to branding was made during the course of establishing an Open Access regime: instead of Österreichische Zeitschrift für Politikwissenschaft, with the abbreviation ÖZP, the journal is now called Austrian Journal of Political Science, with the abbreviation now being OZP. This modification signifies that the journal is actively looking for submissions in English, that it is committed to continue to be a member of high standard academic journals in social sciences in Europe and that it is still embracing its history. In general, since the introduction of the Open Access regime, approximately half of all published articles in the journal are in English, and the tendency is clearly towards more submissions in English than in
German; however, here, again, the quality issue comes into play.

\section{Lessons learnt}

There are two issues about the OZP that distinguish it from other Open Access initiatives in the social sciences. One is that the conversion was driven exclusively by academically more or less well-established representatives from the discipline and not by representatives from the publishing industry. The other is that it has actually been a conversion - not a founding of a new journal, as seems to be the case more often.

Was it worth the effort? I think that, after many years of focusing on academic excellence, more emphasis is put on actual relevance of academic research, and in particular in the social sciences. If that is true, it will become more important again to have infrastructure on the ground that is less oriented towards metrics and profit margins, and instead is able to convey relevant data and research findings to peers as well as to the broader public, while sticking to rigorous qualitative standards that have been established within academia by and large.

The OZP story tells us that Open Access - or, more cautiously, a certain interpretation of how to implement Open Access - could be a decisive step in this direction. It is a change not only in publishing strategy but also in production, as it allows more focus on what is important: quality assurance. Overall, the annual costs for producing the journal are decreasing (and that results in a decrease of financial burdens) while the quality standard has been maintained - more efficient work overall. Open Access, in this interpretation, also means that more free submissions are coming in, with mixed quality, but this is a clear sign that imminent online availability of published texts is of utmost importance to researchers.

Open Access as a new mode of production in journal publishing also allows the journal to remain firmly in the hands of the academics - or, in the words of Michael Hagner, "to return academic publishing to the stewardship of the sciences" (Hagner 2018, 7). This may project a picture of the OZP being a "Gaulish village", but not "selling-out" to major publishers was an important and self-assuring aspect of our decision: not only would it spare us the endemic quality problems, it would also save us from ethical concerns, namely that highly profitable private companies would benefit from the arrangement twice (once, indirectly through the time invested by mostly state-funded academics, and again directly through subscription fees paid by state-funded university libraries).

The latter point of taking responsibility (and production) in our own hands also came with at least one negative aspect: the change management from a printed 
journal to Open Access was more protracted than we had hoped for. Despite the generous funding by FWF and the support from the Innsbruck University, many of those involved continued to operate on an honorary basis. This meant that, when the change process turned out to be difficult (in terms of technical expertise to be acquired and managerial decisions to be made based on sound evidence), there were some delays in publishing a few of the first Open Access journal issues.

Another obstacle that contributed to many headaches back in the time concerned the question what would happen if the FWF grant were to be used up and the contract with the Innsbruck University were to run out. When it comes to resources and funding, one of the major issues (and annoyances) is that much of it is available only in the format of "projects" - otherwise, one is expected to introduce service fees. Introducing an "article processing charge" (ACP) for additional funding was, in my personal opinion, not feasible for a small journal like the OZP, at least not as long as this has not also been established by some other flagship journals in the field. As for the project-funding: yes, you can convert a journal to Open Access and call this a "project"; but when it comes to maintaining this vital publishing infrastructure, it requires institutional backing in the form of a long-term contract specifying rights and commitments. I am therefore more than happy that this has been resolved by the Innsbruck University fulfilling this role.

There is, finally, a broader lesson as well. The time is ripe to reconsider the purposes of academic publishing (Fyfe et al. 2017) and start embracing the opportunities of online communication more thoroughly. For example, we should stop thinking of academic publications as something that is still related to a printed booklet: pre-digital era features, such as "issues", "journals", and so on, may not be the most useful means of communicating research results anymore, given that academics have changed their behaviour of reading so fundamentally. This implies also that there may be need for more sophisticated online communication forums in the social sciences, which then include, but not restrict to, texts that resemble "scientific articles".

\section{References}

Bauer, Bruno/Guido Blechl/Christoph Bock/Patrick Danowski/Andreas Ferus/Anton Graschopf/Thomas König et al. (2015), Recommendations for the Transition to Open Access in Austria, in: Zenodo, Internet: https://doi.org/I0.528I/zenodo.34079 (access: 30/11/2019).

Biagioli, Mario/Alexandra Lippman (eds.) (2020), Gaming the Metrics: Misconduct and Manipulation in Academic Research, Cambridge, MA: MIT Press.
Budapest Open Access Initative (2002), February I4, 2002, Internet: http://www.budapestopenaccessinitiative. org/read (access: 30/II/2019).

Bull, Martin J. (2016), Open Access and Academic Associations in the Political and Social Sciences: Threat or Opportunity?, in: European Political Science, Vol. I5(2), 2OI-2IO.

Fanelli, Daniele (2010), Do Pressures to Publish Increase Scientists' Bias? An Empirical Support from US States Data, in: PLOS ONE, Vol. 5(4), eIO27I.

Fischer, Klaus (2008), Science and Its Malfunctions, in: Human Architecture: Journal of the Sociology of Self-Knowledge, Vol. 6(2), I-22.

Fyfe, Aileen/Kelly Coate/Stephen Curry/Stuart Lawson/ Noah Moxham/Camilla Mørk Røstvik (2017), Untangling Academic Publishing: A History of the Relationship between Commercial Interests, Academic Prestige and the Circulation of Research, in: Zenodo, Internet: https://doi.org/I0.528I/zenodo.546IOo (access: 30/11/2019).

Hagner, Michael (2018), Open Access, Data Capitalism and Academic Publishing, in: Swiss Medical Weekly, Vol. I48(I3-I4), I-8.

Heilbron, Johan/Madeline Bedecarré/Rob Timans (2017), European Journals in the Social Sciences and $\mathrm{Hu}-$ manities, in: Serendipities, Vol. 2(I), 33-49.

König, Thomas (2016), Austrian Political Science in the 2 Ist Century, in: Krauz-Mozer, Barbara /Malgorzata Kulakowska/Piotr Borowiec/Pawel Scigaj(eds.), Political Science in Europe at the Beginning of the 2Ist Century, Kraków: Jagiellonian University Press, 19-38.

König, Thomas/Sonja Puntscher-Riekmann/Gilg Seeber/ Dieter Segert (20I4), Die ÖZP wird zu einem Open Access Journal, in: Österreichische Zeitschrift für Politikwissenschaft, Vol. 43(3), 237-238.

Moore, Samuel/Cameron Neylon/Martin Paul Eve/Daniel Paul O'Donnell/Damian Pattinson (2017), "Excellence R Us": University Research and the Fetishisation of Excellence, in: Palgrave Communications, Vol. 3(I), I-I3.

\section{Author}

Thomas König is researcher and head for strategy and scientific services at the Institute for Advanced Studies, Vienna (IHS). He was member of the editorial team of the OZP between 2012 and 2016 and led the FWF-funded project (grant number OAJ 5O-GII) that converted the journal to Open Access. 